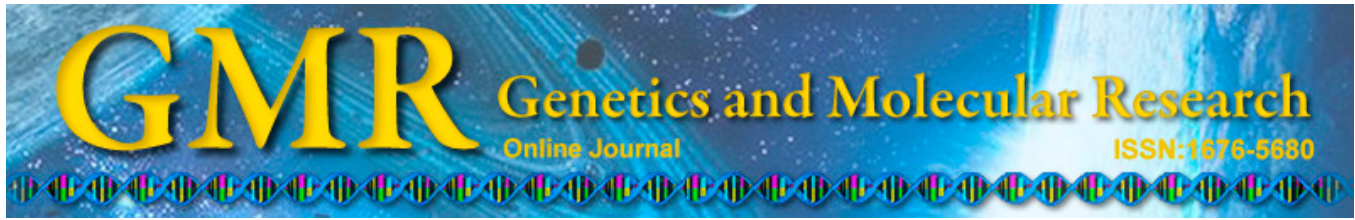

\title{
Vascular endothelial growth factor gene polymorphisms and psoriasis susceptibility: a meta-analysis
}

\author{
Y.H. Lee and G.G. Song \\ Division of Rheumatology, Department of Internal Medicine, \\ Korea University College of Medicine, Seoul, Korea \\ Corresponding author: Y.H. Lee \\ E-mail: lyhcgh@korea.ac.kr \\ Genet. Mol. Res. 14 (4): 14396-14405 (2015) \\ Received June 30, 2015 \\ Accepted October 2, 2015 \\ Published November 18, 2015 \\ DOI http://dx.doi.org/10.4238/2015.November.18.3
}

\begin{abstract}
The aim of this study was to explore whether vascular endothelial growth factor ( $V E G F)$ polymorphisms confer susceptibility to psoriasis. Meta-analyses were conducted to examine the associations between the $+405 \mathrm{C} / \mathrm{G},-460 \mathrm{C} / \mathrm{T},-1154 \mathrm{~A} / \mathrm{G}$, and $-2578 \mathrm{~A} / \mathrm{C}$ polymorphisms of $V E G F$ and psoriasis using allele contrast and recessive, dominant, and additive models. Seven studies on VEGF polymorphisms and psoriasis involving 1956 subjects (psoriasis patients 665, controls 1291) were included in this meta-analysis. We observed no association between psoriasis and the $V E G F+405 \mathrm{C}$ allele in all study subjects (odds ratio $=0.984,95 \%$ confidence interval $=0.754-1.285$, $\mathrm{P}=0.906)$, but stratification by ethnicity indicated a significant association between the $V E G F+405 \mathrm{C}$ allele and psoriasis in Asians (odds ratio $=0.762,95 \%$ confidence interval $=0.628-0.923, \mathrm{P}=0.005)$. In addition, we observed a significant association between the VEGF -460 $\mathrm{C}$ allele and psoriasis in Europeans (odds ratio $=0.807,95 \%$ confidence interval $=0.672-0.968, P=0.021)$. Meta-analyses of the $-1154 \mathrm{~A} / \mathrm{G}$ polymorphism also revealed a significant association with psoriasis in Europeans. However, the $V E G F-2578 \mathrm{~A} / \mathrm{C}$ polymorphism showed no
\end{abstract}


association in all subjects or in Europeans or Asians. This meta-analysis suggests the $V E G F+405 \mathrm{C} / \mathrm{G}$ polymorphism confers susceptibility to psoriasis in Asians, and that the $-460 \mathrm{C} / \mathrm{T}$ and $-1154 \mathrm{~A} / \mathrm{G}$ polymorphisms confer susceptibility to psoriasis in Europeans.

Key words: Meta-analysis; Polymorphism; Psoriasis; Vascular endothelial growth factor

\section{INTRODUCTION}

Psoriasis is a chronic inflammatory skin disorder characterized by keratinocyte hyperproliferation and increased blood flow induced by the stimulation of tissue-resident immune cells by markedly altered cutaneous cytokine profiles (Bhalerao and Bowcock, 1998; Lee et al., 2010). Psoriasis is the most common autoimmune disorder, affecting $0.5-3 \%$ of the general population. Although its etiology is not fully understood, it has been established that psoriasis has a genetic component, and the most powerful genetic factors identified include human leukocyte antigen loci (Nair et al., 2006). However, increasing evidence suggests that non-human leukocyte antigen genes also contribute to psoriasis (Zhang et al., 2009).

Neovascularization plays a key role in the pathogenesis of psoriasis, and vascular endothelial grow factor (VEGF) is considered to be the main angiogenic genetic contributor to this disorder. It has been well-established that VEGF expression is elevated in psoriatic skin (Bhushan et al., 1999), and transgenic mice overexpressing VEGF in the skin develop chronic inflammatory lesions resembling those of psoriasis (Xia et al., 2003). Furthermore, VEGF plasma levels are directly correlated with disease activity (Bhushan et al., 1999).

The VEGF gene is located on chromosome 6p21, which is close to a major psoriasis susceptibility locus; some polymorphisms in the $V E G F$ gene have been shown to influence cytokine production (Vincenti et al., 1996). In addition, the $+405 \mathrm{C} / \mathrm{G}$ (rs2010963), -460 C/T (rs833601), -1154 A/G (rs1570360), and -2578 A/C (rs699947) polymorphisms of VEFG reportedly have functional consequences (Koukourakis et al., 2004). Particularly, the $+405 \mathrm{C} / \mathrm{G}$ polymorphism in the 5 '-untranslated region and 3 polymorphisms in the promoter region (-460 $\mathrm{C} / \mathrm{T},-1154 \mathrm{~A} / \mathrm{G}$, and $-2578 \mathrm{~A} / \mathrm{C}$ ) have been associated with VEGF production (Young et al., 2006). Previous studies showed that these polymorphisms are associated with several autoimmune diseases, including psoriasis, while other reports found no such associations (Young et al., 2004; Barile et al., 2006; Butt et al., 2007; Wang et al., 2008; Wongpiyabovorn et al., 2008; Wu et al., 2010; Zablotna et al., 2013). The reasons for these disparities may be small sample sizes, low statistical power, and/or clinical heterogeneity. Therefore, to overcome the limitations of individual studies, resolve inconsistencies, and reduce the likelihood that random errors were responsible for false-positive or false-negative associations, we conducted a metaanalysis (Lee et al., 2006a,b, 2007). In this present study, we used meta-analysis to examine whether the $+405 \mathrm{C} / \mathrm{G},-460 \mathrm{C} / \mathrm{T},-1154 \mathrm{~A} / \mathrm{G}$, and $-2578 \mathrm{~A} / \mathrm{C}$ polymorphisms of $V E G F$ confer susceptibility to psoriasis.

\section{MATERIAL AND METHODS}

\section{Identification of eligible studies and data extraction}

We performed a search for studies that examined the associations between VEGF 
polymorphisms and psoriasis. The literature was searched using the MEDLINE citation database to identify available articles in which $V E G F$ polymorphisms were analyzed in psoriasis patients. Combinations of keywords, such as, 'vascular endothelial growth factor', 'VEGF', 'polymorphism', and 'psoriasis' were entered as Medical Subject Headings $(\mathrm{MeSH})$ or text words. References in identified studies were also investigated to identify additional studies not indexed by MEDLINE. Genetic association studies that determined the distributions of the $+405 \mathrm{C} / \mathrm{G},-460 \mathrm{C} / \mathrm{T},-1154 \mathrm{~A} / \mathrm{G}$, and $-2578 \mathrm{~A} / \mathrm{C}$ genotypes of VEGF in psoriasis and normal controls were also eligible for inclusion. The following information was extracted from each study: author, year of publication, ethnicity of the study population, demographics, and numbers of cases and controls for each of the $+405 \mathrm{C} / \mathrm{G},-460 \mathrm{C} / \mathrm{T}$, $-1154 \mathrm{~A} / \mathrm{G}$, and $-2578 \mathrm{~A} / \mathrm{C}$ genotypes of VEGF. Frequencies of alleles were calculated from corresponding genotype distributions.

\section{Evaluation of publication bias}

Funnel plots can be used to detect publication bias. However, because of the limitations of funnel plotting, which requires a range of studies of varying sizes involving subjective judgments, we evaluated publication bias using the Egger linear regression test (Egger et al., 1997a), which measures funnel plot asymmetry using a natural logarithm scale of odds ratios (ORs).

\section{Evaluations of statistical associations}

We performed meta-analyses using; 1) the allelic contrast and 2) homozygote contrast techniques and the 3 ) recessive and 4) dominant models. Point estimates of risk, ORs, and 95\% confidence intervals (CIs) were estimated for each study. In addition, within- and between-study variations or heterogeneities were assessed using Cochran's Q-statistic. This heterogeneity test assesses the null hypothesis that all studies evaluated the same effect. The effect of heterogeneity was quantified using $\mathrm{I}^{2}$, which ranges from $0-100 \%$ and represents the proportion of between-study variability that can be attributed to heterogeneity rather than to chance (Higgins and Thompson, 2002). $\mathrm{I}^{2}$ values of 25 , 50 , and $75 \%$ were nominally assigned as low, moderate, and high estimates. The fixedeffect model assumes that genetic factors have similar effects on psoriasis susceptibility across all studies investigated, and that observed variations between studies are caused by chance alone (Egger et al., 1997b). The random-effect model assumes that different studies show substantial diversity and assesses both within-study sampling error and betweenstudy variance (DerSimonian and Laird, 1986). When study groups are homogeneous, the fixed- and random-effect models produce similar results, and when this is not the case, the random-effect model typically provides wider CIs than the fixed-effect model. Thus, the random-effect model is used when significant between-study heterogeneity is present (DerSimonian and Laird, 1986). Statistical manipulations were conducted using a Comprehensive Meta-Analysis computer program (Biosta, Englewood, NJ, USA). The power of each study was computed as the probability of detecting an association between the $V E G F$ polymorphisms and psoriasis at a level of significance of 0.05 , assuming an OR of 1.5 (small effect size). Power analysis was performed using the $\mathrm{G}^{*}$ Power statistical program (http://www.psycho.uni-duesseldorf.de/aap/projects/gpower). 


\section{RESULTS}

\section{Studies included in the meta-analysis}

Ten studies were identified by electronic and manual searching and all 10 were selected for full-text review based on title and abstract details (Young et al., 2004, 2006; Barile et al., 2006; Butt et al., 2007; Lee et al., 2008; Stefanaki et al., 2008; Wang et al., 2008; Wongpiyabovorn et al., 2008; Wu et al., 2010; Zablotna et al., 2013). However, 3 of the 10 were excluded because they had no control group or did not contain genotype data (Young et al., 2006; Lee et al., 2008; Stefanaki et al., 2008). Thus, 7 studies met the study inclusion criteria, and these studies included a total 1956 subjects (psoriasis 665, controls 1291) and consisted of European and Asian populations (Young et al., 2004; Barile et al., 2006; Butt et al., 2007; Wang et al., 2008; Wongpiyabovorn et al., 2008; Wu et al., 2010; Zablotna et al., 2013) (Table 1).

Five studies examined the $+405 \mathrm{C} / \mathrm{G}$ polymorphism, 5 the $-460 \mathrm{C} / \mathrm{T}$ polymorphism, 3 the $-1154 \mathrm{~A} / \mathrm{G}$ polymorphism, and 3 the $-2578 \mathrm{~A} / \mathrm{C}$ polymorphism. Selected characteristics of these studies with respect to associations between $V E G F$ polymorphisms and psoriasis are summarized in Table 1. Meta-analysis was performed to examine the association between these 4 VEGF polymorphisms and psoriasis. In addition, ethnicity-specific meta-analysis was performed in European and Asian populations.

\begin{tabular}{|c|c|c|c|c|c|c|c|c|c|c|c|c|}
\hline \multirow[t]{2}{*}{ Reference } & \multirow[t]{2}{*}{ Ethnicity } & \multirow[t]{2}{*}{ Polymorphism } & \multicolumn{2}{|c|}{ Numbers } & \multicolumn{3}{|c|}{ Case } & \multicolumn{3}{|c|}{ Control } & \multirow{2}{*}{$\begin{array}{c}\text { Association } \\
\text { P value }\end{array}$} & \multirow{2}{*}{ Power $(\%)^{a}$} \\
\hline & & & Case & Control & GG & $\mathrm{GC}$ & $\mathrm{CC}$ & GG & $\mathrm{GC}$ & $\mathrm{CC}$ & & \\
\hline Zablotna, 2013 & European & $+405 \mathrm{C} / \mathrm{G}$ & 189 & 214 & 94 & 81 & 14 & 121 & 86 & 7 & 0.077 & 51.8 \\
\hline $\mathrm{Wu}, 2010$ & Asian & $+405 \mathrm{C} / \mathrm{G}$ & 257 & 258 & 100 & 111 & 46 & 73 & 133 & 52 & 0.037 & 62.1 \\
\hline Wongpiyabovorn, 2008 & Asian & $+405 \mathrm{C} / \mathrm{G}$ & 154 & 234 & 69 & 74 & 11 & 87 & 118 & 29 & 0.066 & 50.3 \\
\hline Barile, 2006 & European & $+405 \mathrm{C} / \mathrm{G}$ & 117 & 215 & 53 & 50 & 14 & 88 & 99 & 28 & 0.484 & 44.5 \\
\hline \multirow[t]{2}{*}{ Young, 2004} & European & $+405 \mathrm{C} / \mathrm{G}$ & 137 & 102 & 50 & 67 & 20 & 47 & 48 & 7 & 0.051 & 33.9 \\
\hline & & & Case & Control & TT & $\mathrm{TC}$ & $\mathrm{CC}$ & TT & $\mathrm{TC}$ & $\mathrm{CC}$ & & \\
\hline Zablotna, 2013 & European & $-460 \mathrm{C} / \mathrm{T}$ & 189 & 215 & 67 & 90 & 32 & 59 & 119 & 37 & 0.235 & 51.9 \\
\hline Wongpiyabovorn, 2008 & Asian & $-460 \mathrm{C} / \mathrm{T}$ & 154 & 234 & 75 & 73 & 6 & 117 & 97 & 20 & 0.613 & 50.3 \\
\hline Wang, 2008 & Asian & $-460 \mathrm{C} / \mathrm{T}$ & 101 & 101 & 44 & 51 & 6 & 49 & 47 & 5 & 0.514 & 29.5 \\
\hline Barile, 2006 & European & $-460 \mathrm{C} / \mathrm{T}$ & 117 & 215 & 33 & 51 & 33 & 39 & 117 & 59 & 0.252 & 44.5 \\
\hline \multirow[t]{2}{*}{ Young, 2004} & European & $-460 \mathrm{C} / \mathrm{T}$ & 137 & 101 & 42 & 74 & 21 & 20 & 60 & 21 & 0.078 & 33.8 \\
\hline & & & Case & Control & GG & GA & AA & GG & GA & AA & & \\
\hline Zablotna, 2011 & European & $-1154 \mathrm{~A} / \mathrm{G}$ & 189 & 215 & 80 & 89 & 20 & 75 & 103 & 37 & 0.040 & 51.9 \\
\hline Wang, 2008 & Asian & $-1154 \mathrm{~A} / \mathrm{G}$ & 100 & 103 & 80 & 18 & 2 & 75 & 27 & 1 & 0.351 & 29.6 \\
\hline \multirow[t]{2}{*}{ Butt, 2007} & European & $-1154 \mathrm{~A} / \mathrm{G}$ & 257 & 147 & 69 & 121 & 67 & 35 & 69 & 43 & 0.395 & 51.9 \\
\hline & & & Case & Control & $\mathrm{CC}$ & $\mathrm{CA}$ & AA & $\mathrm{CC}$ & CA & AA & & \\
\hline Wongpiyabovorn, 2008 & Asian & $-2578 \mathrm{~A} / \mathrm{C}$ & 154 & 234 & 77 & 70 & 7 & 114 & 105 & 15 & 0.634 & 50.3 \\
\hline Wang, 2008 & Asian & $-2578 \mathrm{~A} / \mathrm{C}$ & 101 & 117 & 57 & 44 & 0 & 64 & 53 & 0 & 0.828 & 31.4 \\
\hline Butt, 2007 & European & $-2578 \mathrm{~A} / \mathrm{C}$ & 257 & 150 & 68 & 124 & 65 & 45 & 70 & 35 & 0.449 & 52.2 \\
\hline
\end{tabular}

${ }^{a}$ Assuming an odds ratio of 1.5 (small effect size) at a level of significance of 0.05 .

\section{Heterogeneity and publication bias}

The distributions of genotypes of the $4 V E G F$ polymorphisms in the control groups were consistent with the Hardy-Weinberg equilibrium, except for 1 study (Wang et al., 2008), implying bias in terms of control selection or genotyping errors. However, when 
we excluded this study, overall results were not substantially affected. No between-study heterogeneity was observed during the meta-analyses of the $-460 \mathrm{C} / \mathrm{T},-1154 \mathrm{~A} / \mathrm{G}$, and -2578 $\mathrm{A} / \mathrm{C}$ polymorphisms, but some heterogeneity was found in the meta-analyses of the +405 $\mathrm{C} / \mathrm{G}$ polymorphism for all studies. It was difficult to correlate the funnel plot, which is typically used to detect publication bias, as the number of studies included in the analysis was relatively small. However, the Egger regression test showed no evidence of publication bias (Egger regression test $\mathrm{P}$ values $>0.1$ ).

\section{Meta-analysis of relationship between $+405 \mathrm{C} / \mathrm{G},-460 \mathrm{C} / \mathrm{T},-1154 \mathrm{~A} / \mathrm{G}$, and -2578 $\mathrm{A} / \mathrm{C}$ polymorphisms and psoriasis}

A summary of meta-analyses findings regarding the associations between the 4 polymorphisms and psoriasis is shown in Table 2. In all study subjects, we found no association between psoriasis and the $V E G F+405 \mathrm{C}$ allele $(\mathrm{OR}=0.984,95 \% \mathrm{CI}=0.754-1.285$, $\mathrm{P}=0.906$ ) (Table 2). However, stratification by ethnicity revealed a significant association between the $V E G F+405 \mathrm{C}$ allele and psoriasis in Asians but not in Europeans $(\mathrm{OR}=0.762$, $95 \% \mathrm{CI}=0.628-0.923, \mathrm{P}=0.005 ; \mathrm{OR}=1.186,95 \% \mathrm{CI}=0.974-1.445, \mathrm{P}=0.090)($ Table 2 and Figure 1). We found no association between psoriasis and the $V E G R+405 \mathrm{C} / \mathrm{G}$ polymorphism using the recessive model, but the dominant and additive models showed that this polymorphism, similarly to the $+405 \mathrm{C}$ allele, was associated with psoriasis in Europeans but not in Asians (Table 2).

\begin{tabular}{|c|c|c|c|c|c|c|c|c|}
\hline \multirow[t]{2}{*}{ Polymorphism } & \multirow[t]{2}{*}{ Population } & \multirow[t]{2}{*}{ No. of studies } & \multicolumn{3}{|c|}{ Test of association } & \multicolumn{3}{|c|}{ Test of heterogeneity } \\
\hline & & & OR & $95 \% \mathrm{CI}$ & P value & Model & $\mathrm{P}$ value & $I^{2}$ \\
\hline \multirow[t]{3}{*}{$+405 \mathrm{C} v s \mathrm{G}$} & Overall & 5 & 0.984 & $0.754-1.285$ & 0.906 & $\mathrm{R}$ & 0.006 & 72.4 \\
\hline & European & 3 & 1.186 & $0.974-1.445$ & 0.090 & $\mathrm{~F}$ & 0.103 & 56.0 \\
\hline & Asian & 2 & 0.762 & $0.628-0.923$ & 0.005 & $\mathrm{~F}$ & 0.911 & 0 \\
\hline \multirow[t]{3}{*}{$\mathrm{CC} v s \mathrm{CG}+\mathrm{GG}$ (recessive) } & Overall & 5 & 1.093 & $0.666-1.793$ & 0.724 & $\mathrm{R}$ & 0.043 & 59.3 \\
\hline & European & 3 & 1.498 & $0.936-2.398$ & 0.092 & $\mathrm{~F}$ & 0.143 & 48.5 \\
\hline & Asian & 2 & 0.763 & $0.523-1.111$ & 0.158 & $\mathrm{~F}$ & 0.286 & 12.2 \\
\hline \multirow[t]{3}{*}{$\mathrm{CC}+\mathrm{CG} v s \mathrm{GG}$ (dominant) } & Overall & 5 & 0.925 & $0.664-1.290$ & 0.269 & $\mathrm{R}$ & 0.016 & 67.0 \\
\hline & European & 3 & 1.171 & $0.904-1.516$ & 0.231 & $\mathrm{~F}$ & 0.198 & 38.2 \\
\hline & Asian & 2 & 0.666 & $0.606-0.877$ & 0.004 & $\mathrm{~F}$ & 0.565 & 65.0 \\
\hline \multirow[t]{3}{*}{$\mathrm{CC} v s \mathrm{GG}$} & Overall & 5 & 1.044 & $0.555-1.964$ & 0.894 & $\mathrm{R}$ & 0.007 & 71.8 \\
\hline & European & 3 & 1.702 & $0.756-3.833$ & 0.199 & $\mathrm{~F}$ & 0.073 & 61.7 \\
\hline & Asian & 2 & 0.590 & $0.389-0.896$ & 0.013 & $\mathrm{~F}$ & 0.518 & 0 \\
\hline \multirow[t]{3}{*}{$-460 \mathrm{C} v s \mathrm{~T}$} & Overall & 5 & 0.867 & $0.747-1.005$ & 0.059 & $\mathrm{~F}$ & 0.566 & 0 \\
\hline & European & 3 & 0.807 & $0.672-0.968$ & 0.021 & $\mathrm{~F}$ & 0.777 & 0 \\
\hline & Asian & 2 & 0.998 & $0.773-1.289$ & 0.989 & $\mathrm{~F}$ & 0.409 & 0 \\
\hline \multirow[t]{3}{*}{$\mathrm{CC} v s \mathrm{CT}+\mathrm{TT}$ (recessive) } & Overall & 5 & 0.874 & $0.653-1.171$ & 0.367 & $\mathrm{~F}$ & 0.470 & 0 \\
\hline & European & 3 & 0.927 & $0.675-1.273$ & 0.639 & $\mathrm{~F}$ & 0.608 & 0 \\
\hline & Asian & 2 & 0.635 & $0.302-1.334$ & 0.231 & $\mathrm{~F}$ & 0.190 & 41.7 \\
\hline \multirow[t]{3}{*}{$\mathrm{CC}+\mathrm{CT} v s \mathrm{TT}$ (dominant) } & Overall & 5 & 0.800 & $0.643-0.994$ & 0.044 & $\mathrm{~F}$ & 0.113 & 46.4 \\
\hline & European & 3 & 0.699 & $0.463-0.827$ & 0.001 & $\mathrm{~F}$ & 0.790 & 0 \\
\hline & Asian & 2 & 1.109 & $0.799-1.540$ & 0.536 & $\mathrm{~F}$ & 0.674 & 0 \\
\hline \multirow[t]{3}{*}{$\mathrm{CC} v s \mathrm{TT}$} & Overall & 5 & 0.659 & $0.469-0.925$ & 0.016 & $\mathrm{~F}$ & 0.633 & 0 \\
\hline & European & 3 & 0.652 & $0.446-0.953$ & 0.027 & $\mathrm{~F}$ & 0.653 & 0 \\
\hline & Asian & 2 & 0.688 & $0.322-1.474$ & 0.336 & $\mathrm{~F}$ & 0.193 & 41.1 \\
\hline
\end{tabular}

$\mathrm{OR}=$ odds ratio $; \mathrm{CI}=$ confidence interval $; \mathrm{R}=$ random-effect model $; \mathrm{F}=$ fixed-effect model. 


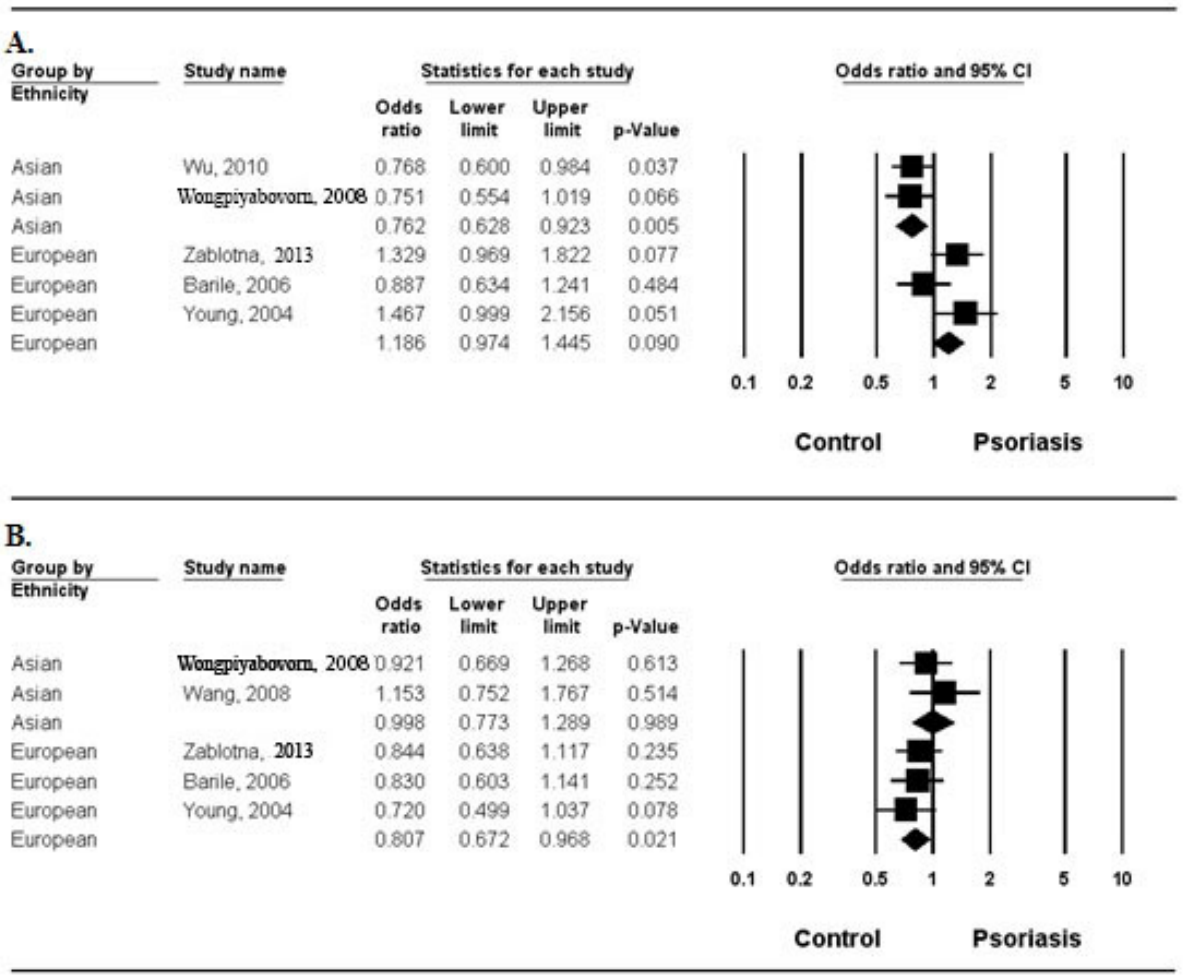

Figure 1. Odds ratios (ORs) and 95\% confidence intervals (CIs) of individual studies and pooled data for allele associations between the $V E G F+405 \mathrm{C} / \mathrm{G}(\mathbf{A})$ and $-460 \mathrm{C} / \mathrm{T}(\mathbf{B})$ polymorphisms and psoriasis in each ethnic group.

We observed no association between psoriasis and the $V E G F-460 \mathrm{C}$ allele $(\mathrm{OR}=$ $0.867,95 \% \mathrm{CI}=0.747-1.005, \mathrm{P}=0.059)$ (Table 2 ). However, stratification by ethnicity indicated a significant association between the $V E G F-460 \mathrm{C}$ allele and psoriasis in Europeans but not in Asians $(\mathrm{OR}=0.807,95 \% \mathrm{CI}=0.672-0.968, \mathrm{P}=0.021 ; \mathrm{OR}=0.998,95 \% \mathrm{CI}=0.773$ $1.289, \mathrm{P}=0.989$ ) (Table 2 and Figure 1). We found no association between psoriasis and the $V E G R-460 \mathrm{C} / \mathrm{T}$ polymorphism using the recessive model, but the dominant and the additive models showed the same pattern as the results for the $-460 \mathrm{C}$ allele, which showed a significant association in Europeans but not in Asians (Table 2).

In all study subjects, meta-analysis showed a significant association between psoriasis and the $V E G F-1154$ A allele $(\mathrm{OR}=0.803,95 \% \mathrm{CI}=0.663-0.972, \mathrm{P}=0.025)($ Table 3$)$. Stratification by ethnicity revealed a significant association between the $V E G F-1154$ A allele and psoriasis in Europeans but not in Asians $(\mathrm{OR}=0.808,95 \% \mathrm{CI}=0.660-0.990, \mathrm{P}=0.040$; OR $=0.754,95 \% \mathrm{CI}=0.417-1.363, \mathrm{P}=0.351)$ (Table 3 and Figure 2$)$. We found no association between psoriasis and the VEGR $-1154 \mathrm{~A} / \mathrm{G}$ polymorphism using the recessive or dominant models, but meta-analyses using the additive model showed the same pattern as the metaanalysis of the -1154 A allele, showing a significant association in Europeans but not in Asians (Table 3). We found no association between psoriasis and the $V E G F-2578 \mathrm{~A} / \mathrm{C}$ polymorphism using the allelic contrast, recessive, dominant, or additive models in all study subjects or in Europeans or Asians (Table 3). 


\begin{tabular}{|c|c|c|c|c|c|c|c|c|}
\hline \multirow[t]{2}{*}{ Polymorphism } & \multirow[t]{2}{*}{ Population } & \multirow[t]{2}{*}{ No. of studies } & \multicolumn{3}{|c|}{ Test of association } & \multicolumn{3}{|c|}{ Test of heterogeneity } \\
\hline & & & OR & $95 \% \mathrm{CI}$ & P value & Model & $\mathrm{P}$ value & $P^{2}$ \\
\hline \multirow[t]{3}{*}{$-1154 \mathrm{~A} v s \mathrm{G}$} & Overall & 3 & 0.803 & $0.663-0.972$ & 0.025 & $\mathrm{~F}$ & 0.680 & 0 \\
\hline & European & 2 & 0.808 & $0.660-0.990$ & 0.040 & $\mathrm{~F}$ & 0.395 & 0 \\
\hline & Asian & 1 & 0.754 & $0.417-1.363$ & 0.351 & NA & NA & NA \\
\hline \multirow{3}{*}{$\mathrm{AA} v s \mathrm{AG}+\mathrm{GG}$ (recessive) } & Overall & 3 & 0.750 & $0.527-1.067$ & 0.110 & $\mathrm{~F}$ & 0.396 & \\
\hline & European & 2 & 0.732 & $0.513-1.048$ & 0.088 & $\mathrm{~F}$ & 0.283 & 13.2 \\
\hline & Asian & 1 & 2.082 & $0.186-23.32$ & 0.552 & NA & NA & NA \\
\hline \multirow[t]{3}{*}{$\mathrm{AA}+\mathrm{AG} v s \mathrm{GG}$ (dominant) } & Overall & 3 & 0.758 & $0.575-1.000$ & 0.050 & $\mathrm{~F}$ & 0.816 & 0 \\
\hline & European & 2 & 0.779 & $0.574-1.057$ & 0.109 & $\mathrm{~F}$ & 0.625 & 0 \\
\hline & Asian & 1 & 0.670 & $0.348-1.289$ & 0.230 & NA & NA & NA \\
\hline \multirow[t]{3}{*}{ AA $v s$ GG } & Overall & 3 & 0.670 & $0.444-1.011$ & 0.056 & $\mathrm{~F}$ & 0.409 & 0 \\
\hline & European & 2 & 0.650 & $0.428-0.986$ & 0.043 & $\mathrm{~F}$ & 0.300 & 6.80 \\
\hline & Asian & 1 & 1.875 & $0.167-21.10$ & 0.611 & NA & NA & NA \\
\hline \multirow{3}{*}{$-2578 \mathrm{~A}$ vs $\mathrm{C}$} & Overall & 3 & 1.013 & $0.835-1.229$ & 0.894 & $\mathrm{~F}$ & 0.660 & 0 \\
\hline & European & 1 & 1.116 & $0.839-1.485$ & 0.449 & NA & NA & NA \\
\hline & Asian & 2 & 0.934 & $0.719-1.213$ & 0.607 & $\mathrm{~F}$ & 0.922 & 0 \\
\hline \multirow[t]{3}{*}{$\mathrm{AA} v s \mathrm{AC}+\mathrm{CC}$ (recessive) } & Overall & 2 & 1.009 & $0.663-1.535$ & 0.967 & $\mathrm{~F}$ & 0.373 & 0 \\
\hline & European & 1 & 1.112 & $0.694-1.782$ & 0.658 & NA & NA & NA \\
\hline & Asian & 1 & 0.695 & $0.227-1.747$ & 0.439 & NA & NA & NA \\
\hline \multirow[t]{3}{*}{$\mathrm{AA}+\mathrm{AC} v s \mathrm{CC}$ (dominant) } & Overall & 3 & 1.023 & $0.787-1.329$ & 0.867 & $\mathrm{~F}$ & 0.708 & 0 \\
\hline & European & 1 & 1.191 & $0.763-1.860$ & 0.442 & NA & NA & NA \\
\hline & Asian & 2 & 0.943 & $0.682-1.304$ & 0.725 & $\mathrm{~F}$ & 0.956 & 0 \\
\hline \multirow[t]{3}{*}{$\mathrm{AA} v s \mathrm{Cc}$} & Overall & 2 & 1.059 & $0.655-1.710$ & 0.816 & $\mathrm{~F}$ & 0.303 & 5.89 \\
\hline & European & 1 & 1.229 & $0.704-2.146$ & 0.468 & NA & NA & NA \\
\hline & Asian & 1 & 0.691 & $0.269-1.773$ & 0.442 & NA & NA & NA \\
\hline
\end{tabular}

$\mathrm{OR}=$ odds ratio $; \mathrm{CI}=$ confidence interval $; \mathrm{R}=$ random-effect model $; \mathrm{F}=$ fixed-effect model $; \mathrm{NA}=$ not available.

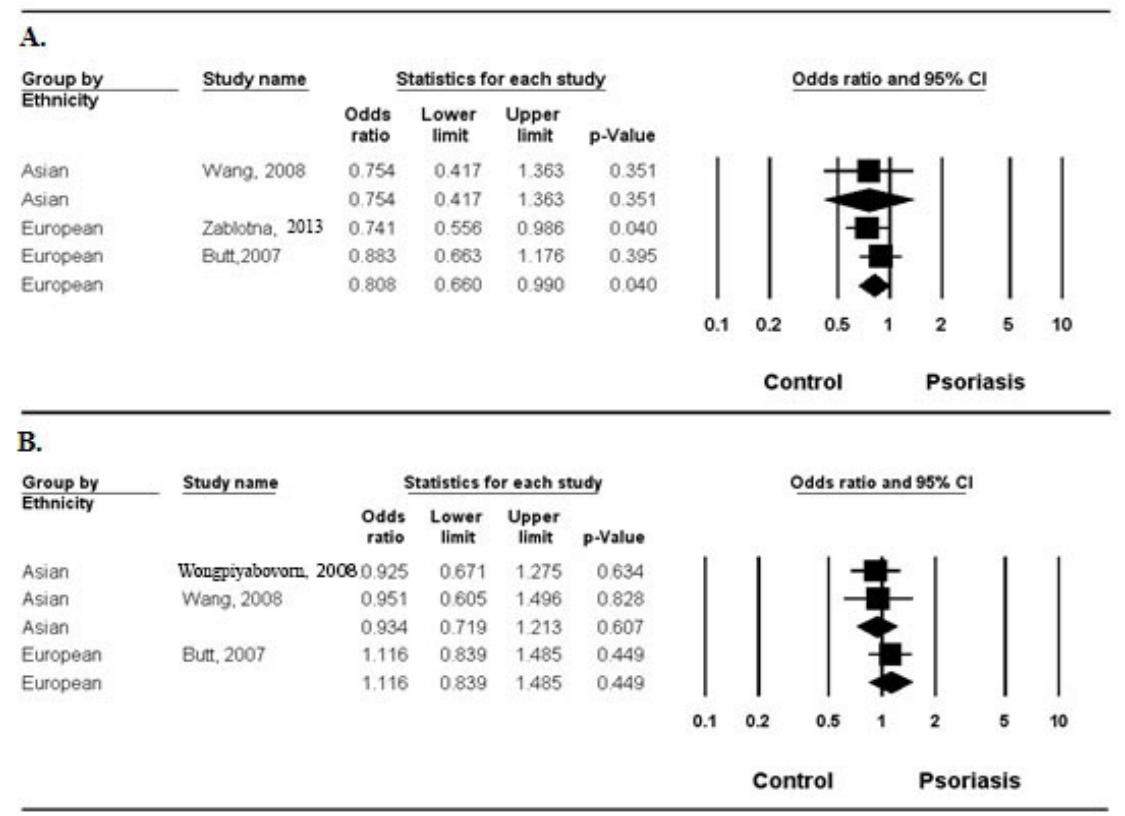

Figure 2. Odds ratios (ORs) and 95\% confidence intervals (CIs) of individual studies and pooled data for allele associations between the $V E G F-1154 \mathrm{~A} / \mathrm{G}(\mathrm{A})$ and $-2578 \mathrm{~A} / \mathrm{C}(\mathbf{B})$ polymorphisms and psoriasis in each ethnic group. 


\section{DISCUSSION}

Although association studies are excellent for identifying genetic factors that confer susceptibility to common diseases such as psoriasis, most of the reported association studies are underpowered in terms of detecting modest genetic effects that underlie susceptibilities to common diseases (Lohmueller et al., 2003). This results in inconsistent findings because of false-positive, false-negative, or true association variability in different populations. Metaanalysis integrates previous research and increases the statistical power and resolution by pooling the results of independent analyses (Lee et al., 2006a, 2007), providing a powerful means of overcoming the small sample size problem and the often inadequate statistical powers of genetic studies of complex traits.

Although the multifactorial nature of psoriasis is well known, genetic factors are considered to be strong determinants of these diseases, and thus studies have been encouraged to search for the genes responsible. Several genes have been studied for this reason, and the $V E G F$ gene is one such gene in the context of psoriasis (Vincenti et al., 1996). VEGF plays a key role in angiogenesis and contributes to immune system regulation. Given the potential link between VEGF and autoimmune diseases, VEGF polymorphisms, which may influence VEGF expression, have been studied as potential causes of autoimmune diseases (Watson et al., 2000). VEGF acts as a potent mediator of angiogenesis and inflammation and is known to be overexpressed in the psoriatic epidermis (Schön, 1999). Furthermore, VEGF is thought to participate in the pathogenesis of psoriasis. For example, transgenic mice over-expressing VEGF in the epidermis developed skin lesions with psoriatic features; retinoids, which are widely used to treat psoriasis, have shown to inhibit VEGF-induced angiogenesis (Xia et al., 2003; Young et al., 2006). Furthermore, VEGF levels in the blood have been correlated with psoriasis activity (Bhushan et al., 1999). VEGF expression is affected by genetic factors, and the $+405 \mathrm{C} / \mathrm{G},-460 \mathrm{C} / \mathrm{T},-1154 \mathrm{~A} / \mathrm{G}$, and $-2578 \mathrm{~A} / \mathrm{C}$ polymorphisms have been reported to influence VEGF production and to be associated with other inflammatory diseases. Particularly, +405 has been reported to be a myeloid zinc finger protein (MZF1)-binding site, and it has been suggested that its $\mathrm{C}$ allele decreases $V E G F$ gene transcription and protein production (Lip and Chung, 2005). Young et al. (2004) showed that the $+405 \mathrm{CC}$ and $-460 \mathrm{TT}$ genotypes are associated with early-onset psoriasis and high VEGF expression in peripheral blood mononuclear cells. Furthermore, the $-2578 \mathrm{~A} / \mathrm{C}$ polymorphism is thought to be a GATA-2 binding site, and the $-2578 \mathrm{~A}$ and $-460 \mathrm{~T}$ alleles were reported to be associated with high VEGF expression in the plasma (Lip and Chung, 2005). Finally, the $-1154 \mathrm{~A} / \mathrm{G}$ polymorphism is associated with VEGF production by stimulated peripheral mononuclear cells (Zablotna et al., 2013).

In this meta-analysis, we combined data from published studies to evaluate genetic associations between psoriasis and the most commonly studied polymorphisms of the VEGF gene, including $+405 \mathrm{C} / \mathrm{G},-460 \mathrm{C} / \mathrm{T},-1154 \mathrm{~A} / \mathrm{G}$, and $-2578 \mathrm{~A} / \mathrm{C}$. Our meta-analysis of the VEGF $-2578 \mathrm{~A} / \mathrm{C}$ polymorphism revealed no association with psoriasis in all study subjects or in Europeans or Asians. However, a significant association between the $V E G F+405 \mathrm{C}$ allele and psoriasis was observed in Asians but not in Europeans, suggesting that the $\mathrm{C}$ allele is a protective factor with an $\mathrm{OR}$ of $0.762(95 \% \mathrm{CI}=0.628-0.923, \mathrm{P}=0.005)$. We also found a significant association between the $460 \mathrm{C}$ allele and psoriasis in Europeans but not in Asians $(\mathrm{OR}=0.807,95 \% \mathrm{CI}=0.672-0.968, \mathrm{P}=0.021 ; \mathrm{OR}=0.998,95 \% \mathrm{CI}=0.773-1.289, \mathrm{P}=0.989)$. Furthermore, the $-1154 \mathrm{~A} / \mathrm{G}$ polymorphism showed a significant association with psoriasis in Europeans and Asians, suggesting that the $-460 \mathrm{C}$ and $-1154 \mathrm{~A}$ alleles are protective factors 
with ORs of $0.807(95 \% \mathrm{CI}=0.672-0.968, \mathrm{P}=0.021)$ and $0.803(95 \% \mathrm{CI}=0.663-0.972, \mathrm{P}=$ $0.025)$, respectively.

There were some limitations to this study. First, heterogeneity and confounding factors may have distorted the analysis. Furthermore, publication bias may have adversely affected the analysis, as studies that produced negative results may not have been published or may have been missed; although the Egger regression test was used, the possibility of bias cannot be eliminated. Second, ethnicity-specific analysis was performed using European and Asian data, and thus our results are only applicable to these ethnic groups. Third, haplotype analysis may have provided more information and would have been more powerful than single polymorphism analysis. For example, Wongpiyabovorn et al. (2008) showed that the -2578 $\mathrm{C} /-460 \mathrm{~T} / 405 \mathrm{G}$ haplotype is a marker for susceptibility to psoriasis. Furthermore, the +405 $\mathrm{C} / \mathrm{G}$ and $-460 \mathrm{C} / \mathrm{T}$ polymorphisms were found to be in linkage disequilibrium. However, unfortunately, no meta-analysis of haplotypes was possible because of inadequate haplotype data. Fourth, the $V E G F$ polymorphisms examined may be associated with psoriasis severity, but the small amount of data available did not allow us to investigate these associations.

In conclusion, this meta-analysis showed that the $V E G F+405 \mathrm{C} / \mathrm{G}$ confers susceptibility to psoriasis in Asians. Furthermore, the $-460 \mathrm{C} / \mathrm{T}$ and $-1154 \mathrm{~A} / \mathrm{G}$ polymorphisms were found to confer susceptibility to psoriasis in Europeans. These findings prompt further investigation of the associations between VEGF polymorphisms and psoriasis susceptibility. Particularly, larger scale studies in populations with different ethnicities are necessary to explore the roles of VEGF polymorphisms in the pathogenesis of psoriasis.

\section{REFERENCES}

Barile S, Medda E, Nisticò L, Bordignon V, et al. (2006). Vascular endothelial growth factor gene polymorphisms increase the risk to develop psoriasis. Exp. Dermatol. 15: 368-376.

Bhalerao J and Bowcock AM (1998). The genetics of psoriasis: a complex disorder of the skin and immune system. Hum. Mol. Genet. 7: 1537-1545.

Bhushan M, McLaughlin B, Weiss JB and Griffiths CE (1999). Levels of endothelial cell stimulating angiogenesis factor and vascular endothelial growth factor are elevated in psoriasis. Br. J. Dermatol. 141: 1054-1060.

Butt C, Lim S, Greenwood C and Rahman P (2007). VEGF, FGF1, FGF2 and EGF gene polymorphisms and psoriatic arthritis. BMC Musculoskelet. Disord. 8: 1.

DerSimonian R and Laird N (1986). Meta-analysis in clinical trials. Control. Clin. Trials 7: 177-188.

Egger M, Davey Smith G, Schneider M and Minder C (1997a). Bias in meta-analysis detected by a simple, graphical test. BMJ 315: 629-634.

Egger M, Smith GD and Phillips AN (1997b). Meta-analysis: principles and procedures. BMJ 315: 1533-1537.

Higgins JP and Thompson SG (2002). Quantifying heterogeneity in a meta-analysis. Stat. Med. 21: 1539-1558.

Koukourakis MI, Papazoglou D, Giatromanolaki A, Bougioukas G, et al. (2004). VEGF gene sequence variation defines VEGF gene expression status and angiogenic activity in non-small cell lung cancer. Lung Cancer 46: 293-298.

Lee JH, Cho EY, Namkung JH, Kim E, et al. (2008). Single-nucleotide polymorphisms and haplotypes in the VEGF receptor 3 gene and the haplotype GC in the VEGFA gene are associated with psoriasis in Koreans. J. Invest. Dermatol. 128: 1599-1603.

Lee KH, Son MK, Ha YJ, Choi ST, et al. (2010). Inflammatory polyarthritis in a patient with psoriasis: is it psoriatic arthritis or rheumatoid arthritis? Korean J. Intern. Med. 25: 224-226.

Lee YH, Harley JB and Nath SK (2006a). Meta-analysis of TNF-alpha promoter -308 A/G polymorphism and SLE susceptibility. Eur. J. Hum. Genet. 14: 364-371.

Lee YH, Rho YH, Choi SJ, Ji JD, et al. (2006b). Association of TNF-alpha -308 G/A polymorphism with responsiveness to TNF-alpha-blockers in rheumatoid arthritis: a meta-analysis. Rheumatol. Int. 27: 157-161.

Lee YH, Rho YH, Choi SJ, Ji JD, et al. (2007). The PTPN22 C1858T functional polymorphism and autoimmune diseases - a meta-analysis. Rheumatology 46: 49-56.

Lip GY and Chung I (2005). Vascular endothelial growth factor and angiogenesis in heart failure. J. Card. Fail. 11: 285-287. 
Lohmueller KE, Pearce CL, Pike M, Lander ES, et al. (2003). Meta-analysis of genetic association studies supports a contribution of common variants to susceptibility to common disease. Nat. Genet. 33: 177-182.

Nair RP, Stuart PE, Nistor I, Hiremagalore R, et al. (2006). Sequence and haplotype analysis supports HLA-C as the psoriasis susceptibility 1 gene. Am. J. Hum. Genet. 78: 827-851.

Schön MP (1999). Animal models of psoriasis - what can we learn from them? J. Invest. Dermatol. 112: 405-410.

Stefanaki I, Dimisianos G, Antoniou C, Katsambas A, et al. (2008). Investigation of +405 and -460 polymorphisms of vascular endothelial growth factor in psoriasis and short-term responsiveness to efalizumab therapy. Dermatology 217: 201-202.

Vincenti V, Cassano C, Rocchi M and Persico G (1996). Assignment of the vascular endothelial growth factor gene to human chromosome 6p21.3. Circulation 93: 1493-1495.

Wang Z, Liang W, Zhang B, Lv M, et al. (2008). Single nucleotide polymorphisms of VEGF gene and psoriasis risk. $J$. Dermatol. Sci. 49: 263-265.

Watson CJ, Webb NJ, Bottomley MJ and Brenchley PE (2000). Identification of polymorphisms within the vascular endothelial growth factor (VEGF) gene: correlation with variation in VEGF protein production. Cytokine 12: 1232-1235.

Wongpiyabovorn J, Yooyongsatit S, Ruchusatsawat K, Avihingsanon Y, et al. (2008). Association of the CTG (-2578/460/+405) haplotype within the vascular endothelial growth factor gene with early-onset psoriasis. Tissue Antigens 72: 458-463.

Wu J, Ren X, Zhang X, Li C, et al. (2010). The vascular endothelial growth factor $+405 \mathrm{G} / \mathrm{C}$ polymorphism in psoriasis. J. Dermatol. Sci. 57: 62-63.

Xia YP, Li B, Hylton D, Detmar M, et al. (2003). Transgenic delivery of VEGF to mouse skin leads to an inflammatory condition resembling human psoriasis. Blood 102: 161-168.

Young HS, Summers AM, Bhushan M, Brenchley PE, et al. (2004). Single-nucleotide polymorphisms of vascular endothelial growth factor in psoriasis of early onset. J. Invest. Dermatol. 122: 209-215.

Young HS, Summers AM, Read IR, Fairhurst DA, et al. (2006). Interaction between genetic control of vascular endothelial growth factor production and retinoid responsiveness in psoriasis. J. Invest. Dermatol. 126: 453-459.

Zablotna M, Sobjanek M, Nedoszytko B, Lange M, et al. (2013). Association of psoriasis with the VEGF gene polymorphism in the northern Polish population. J. Eur. Acad. Dermatol. Venereol. 27: 319-323.

Zhang XJ, Huang W, Yang S, Sun LD, et al. (2009). Psoriasis genome-wide association study identifies susceptibility variants within LCE gene cluster at 1q21. Nat. Genet. 41: 205-210. 